Open Access

Original Article

\title{
Prevalence of antenatal depression among women receiving antenatal care during last trimester of pregnancy in a tertiary care private institute of Lahore
}

\author{
Mahrukh Sabir ${ }^{1}$, Muhammad Luqman Farrukh Nagi², \\ Tahseen Haider Kazmi ${ }^{3}$
}

\begin{abstract}
Objective: Pregnancy and depression affect each other. The main objective of our study was to find out frequency of antenatal depression during last trimester and associated risk factors among pregnant female visiting a tertiary care private institution of Lahore, Pakistan.

Methods: This study was conducted at Shalamar Hospital a private tertiary care institution of Lahore during May 2017 to June 2018. Assuming 18\% prevalence with design effect 1.5 and $97 \%$ confidence interval the calculated sample size was 417 . To avoid dropouts the questionnaire was administered to 450 pregnant females in their last trimester that is with gestational age above 28 weeks. In this study we used a modified version of Goldberg's depression scale in Urdu language for data collection. Wherever needed the data collection team read out aloud the questionnaire to the participants who did not know how to read and write. Informed consent in a written form (in Urdu language) was taken from every study participant after explaining the participants about the research. If the participant did not know how to read and write, the interviewers narrated out aloud the script of informed consent for them and got it signed later by the participants. The confidentiality, anonymity and privacy of the study participants were preserved. Ethical approval of this study was obtained from Institutional Review Board of Shalamar Institute of Health Sciences. Data entry and analysis was finalized by using SPSS version 20.

Results: The prevalence of depression among women seeking antenatal care during their last trimester according to Goldberg Depression Scale was 40.89\% ( $n=184)$. Whereas, 30.4\% $(n=137), 8.67 \%(n=39)$ and $1.78 \%(n=8)$ suffered from mild, moderate and severe depression respectively. The associations between passive smoking $(p<0.01)$, family history of preeclampsia $(p<0.05)$ and depression among family members $(\mathrm{p}<0.05)$ with antenatal depression during last trimester were significant.

Conclusion: According to Goldberg Depression Scale, $40.89 \%(n=184)$ of pregnant women seeking antenatal care in private tertiary care institution of Lahore suffered from depression.
\end{abstract}

KEYWORDS: Antenatal depression, Passive smoking, Goldberg Depression Scale, Third trimester.

doi: https://doi.org/10.12669/pjms.35.2.649

How to cite this:

Sabir M, Nagi MLF, Kazmi TH. Prevalence of antenatal depression among women receiving antenatal care during last trimester of pregnancy in a tertiary care private institute of Lahore. Pak J Med Sci. 2019;35(2):527-531.

doi: https://doi.org/10.12669/pjms.35.2.649

This is an Open Access article distributed under the terms of the Creative Commons Attribution License (http://creativecommons.org/licenses/by/3.0), which permits unrestricted use, distribution, and reproduction in any medium, provided the original work is properly cited.

Correspondence:

Dr. Muhammad Luqman Farrukh Nagi,

Assistant Professor, Dept. of Community Medicine,

Shalamar Medical and Dental College, Lahore, Pakistan.

Email: luqman.farrukh@sihs.org.pk luqmannagy@gmail.com

* Received for Publication:

September 14, 2018

* $1^{\text {st }}$ Revision Received:

* $2^{\text {nd }}$ Revision Received:

* Final Revision Accepted:
October 2, 2018

January 29, 2019

January 31, 2019

\section{INTRODUCTION}

In pregnancy there are chief physiological as well as psychological episode. ${ }^{1}$ Pregnancy and depression influence each other. ${ }^{2}$ Depression is an affective disorder, it is also characterized by sustained sorrow and noticeable anhedonia in daily routine as chief symptoms prevailing for one or more than one week. Additional alarming 
signs are sense of worthlessness, feeling offended and irritable, sleeplessness, appetite variations, diminished energy, poor concentration, decreased memory, and feelings of suicidal attempt or abortion. ${ }^{3}$ Depression is a frequent psychological infirmity ranking the third most common disabling disorder universally by the World Health Organization. ${ }^{4}$ Antenatal depression can be a precursor of postpartum depression. ${ }^{5}$ Pregnant mothers with prenatal depression are less probable to attend antenatal assessment, which contributes to unfavorable pregnancy outcomes for example preterm birth, low birth weight and intrauterine growth retardation. ${ }^{6-8}$ Depressed pregnant women are more likely to suffer from obstetrical impediments like pre-eclampsia. ${ }^{9,10}$

The children of mother with depression may experience impaired neurological, cognitive, emotional, and behavioral growth. ${ }^{11}$ A large number of epidemiological studies have revealed that 10$15 \%$ of women of childbearing age show depressive symptoms. ${ }^{11,12}$ The highest prevalence estimates of antepartum suicidal ideation (23-33\%) have been accounted in studies conducted in the United States. ${ }^{13}$ The prevalence of antenatal depression was $14.2 \%$ in Brazil ${ }^{14} 19 \%$ in Jordan, $15.5 \%$ in Malta, ${ }^{15} 25 \%$ in Jamaica, more than $48.4 \%$ in Pakistan. ${ }^{16-17}$

There is scarcity of research to assess the antenatal depression among women seeking antenatal care in tertiary care private institutions of Lahore. The purpose of this study was to find out frequency of perinatal depression and its associated risk factors among women during pregnancy in a tertiary care private institution of Lahore, Pakistan.

\section{METHODS}

Convenience sampling technique was used in this cross sectional study, conducted at Shalamar Hospital a private tertiary care institution of Lahore during May 2017 to June 2018 after Ethical Approval by Institutional Review Board of Shalamar Institute of Health Sciences. Karmaliani $\mathrm{R}$ et al. in 2009 screened all pregnant women living in identified areas of Hyderabad, Pakistan using a validated Aga Khan University Anxiety Depression Scale found out that $18 \%$ of the women were anxious and/or depressed. ${ }^{18}$ Assuming 18\% prevalence of depression, with design effect 1.5 and at $97 \%$ confidence interval the calculated sample size was 417. To avoid dropouts the questionnaire was administered to 450 pregnant females in their last trimester that is with gestational age above 28 weeks. Data was collected through a close ended questionnaire based on Goldberg's depression scale from expectant females after getting informed consent. Both informed consent and Goldberg's depression scale were taken on the forms translated in Urdu language. Informed consent in a written form (in Urdu language) was taken from every study participant after explaining the participants about the research. If the participants did not know how to read and write, the interviewers narrated out aloud the script of informed consent for them and got it signed later by the participants. In this study we used a modified version of Goldberg's depression scale translated in Urdu language for data collection. Wherever needed the data collection team read out aloud the questionnaire to the participants who did not know how to read and write. The confidentiality and privacy of the participants was preserved by coding of data. Goldberg's depression scale is a validated tool used for screening of depression. Based on the scores, the participants who scored above 21 were counseled and referred to the psychiatry department for management. Data entry and analyses were done in SPSS for Windows version 20. All results were regarded statistically significant having $p$ value less than 0.05 .

Table-I: Basic profile of study participants $(n=450)$.

\begin{tabular}{|c|c|c|}
\hline \multicolumn{2}{|c|}{ Characteristics } & \multirow{2}{*}{$\begin{array}{c}N(\%) \\
137(30.4 \%)\end{array}$} \\
\hline \multirow{5}{*}{ 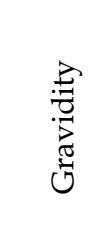 } & 1 & \\
\hline & 2 & $121(26.9 \%)$ \\
\hline & 3 & $85(18.9 \%)$ \\
\hline & 4 & $61(13.6 \%)$ \\
\hline & 5 and more & $46(10.2 \%)$ \\
\hline \multirow{5}{*}{ 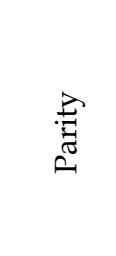 } & 0 & $169(37.6 \%)$ \\
\hline & 1 & $124(27.6 \%)$ \\
\hline & 2 & $87(19.3 \%)$ \\
\hline & 3 & $47(10.4 \%)$ \\
\hline & 4 & $23(5.1 \%)$ \\
\hline \multirow{3}{*}{ 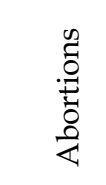 } & 0 & $332(73.8 \%)$ \\
\hline & 1 & $86(19.1 \%)$ \\
\hline & 2 & $32(7.1 \%)$ \\
\hline \multirow{6}{*}{ 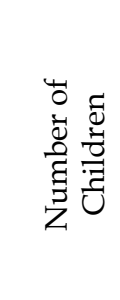 } & 0 & $184(40.9 \%)$ \\
\hline & 1 & $123(27.3 \%)$ \\
\hline & 2 & $87(19.3 \%)$ \\
\hline & 3 & $36(8.0 \%)$ \\
\hline & 4 & $20(4.4 \%)$ \\
\hline & 5 & $13(2.9 \%)$ \\
\hline
\end{tabular}




\section{RESULTS}

The response rate was $100 \%(n=450)$. The mean age of study participants was $27.5 \pm 4.3$. The average height in inches was $61.8 \pm 2.4$. Prepregnancy weight in kilograms was $63 \pm 13$. The average Body Mass Index at third trimester was 30.5 \pm 5.6 . Additional maternal profile is given in Table-I. Almost $81.3 \%(n=366)$ of the women had a family income of less than 50,000 Pakistan Rupees (equal to US \$ 387.5 per month) (Table-II). Another 63\% $(n=282)$ had a distant or close family member suffering from Diabetes Mellitus. A worrying $17.1 \% \quad(n=77)$ claimed of having a history of congenital abnormalities running in the family (Table-II). The prevalence of depression among women seeking antenatal care during their last trimester according to Goldberg Depression Scale was $40.89 \%(n=184)$ (Fig.1). On the other hand, $30.4 \%(n=137), 8.67 \%(n=39)$ and $1.78 \%(\mathrm{n}=8)$ suffered from mild, moderate and severe depression respectively.

Almost $24.4 \% 9 \quad(n=110)$ of the women during their last trimester of pregnancy for the antenatal checkup admitted to suffer from passive smoking, whereas the association between passive smoking and antenatal depression in last trimester was highly significant $(p<0.01)$. About $26.6 \% \quad(n=120)$ had a family history of pre eclampsia and the association between family history of preeclampsia and antenatal depression was highly significant

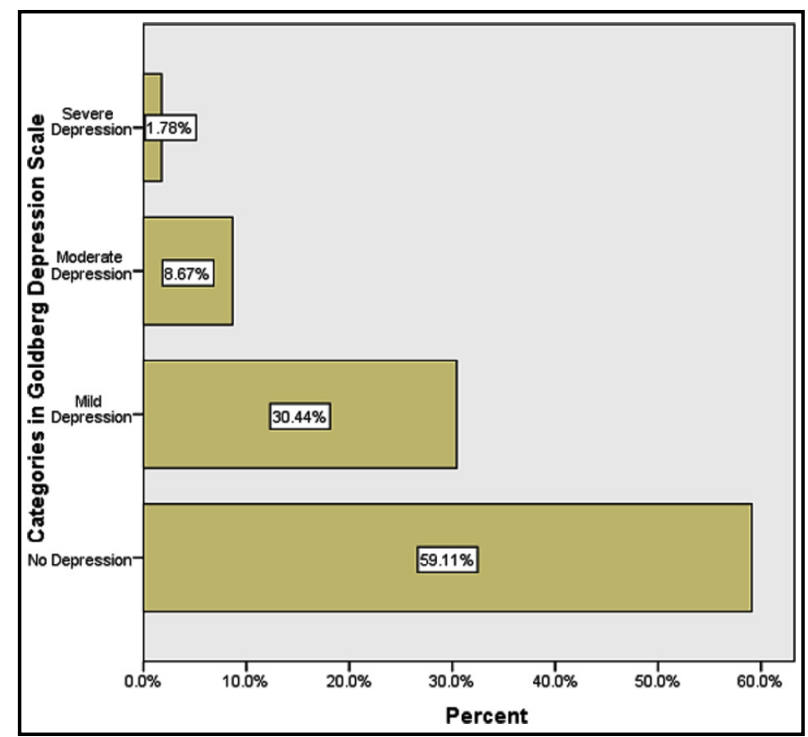

Fig.1: Frequency of depression among pregnant females in last trimester of pregnancy according to Goldberg Depression Scale $(n=450)$.

$(\mathrm{p}<0.05)$. Almost $16.8 \%(\mathrm{n}=76)$ of the women had a family history of depression and the association was significant $(\mathrm{p}<0.05)$ (Table-II).

\section{DISCUSSION}

In a study conducted in Hyderabad, Sindh the frequency of depression during pregnancy $(n=1.368)$ was found to be $18 \%$ using Aga Khan University Anxiety Depression Scale (AKUADS)

Table-II: Associations of study participants with depression $(n=450)$.

\begin{tabular}{llccr}
\hline \multirow{2}{*}{ Characteristics } & & \multicolumn{2}{c}{ Depression } & \multirow{2}{*}{ P value } \\
\cline { 3 - 4 } & & Yes n (\%) & No n (\%) & \\
\hline \multirow{3}{*}{ Family income } & Less than 25000 PKR & $70(15.6 \%)$ & $107(23.8 \%)$ & \\
& $25000-50000$ PKR & $84(18.7 \%)$ & $105(23.3 \%)$ & 0.359 \\
& $\geq 50000$ PKR & $30(6.6 \%)$ & $54(12 \%)$ & \\
Passive Smoker & Yes & $65(14.4 \%)$ & $45(10 \%)$ & \multirow{2}{*}{$0.000^{*}$} \\
& No & $119(26.4 \%)$ & $221(49.1 \%)$ & \\
Congenital Abnormalities in Family & Yes & $31(6.9 \%)$ & $46(10.2 \%)$ & \multirow{2}{*}{0.902} \\
& No & $153(34.0 \%)$ & $220(48.9 \%)$ & \\
Family History of Pre-eclampsia & Yes & $65(14.4 \%)$ & $55(12.2 \%)$ & $0.001^{*}$ \\
& No & $119(26.4 \%)$ & $211(47 \%)$ & \\
Family History of Depression & Yes & $40(8.9 \%)$ & $36(8.0 \%)$ & $0.022^{*}$ \\
& No & $144(32 \%)$ & $230(51.1 \%)$ & \\
Family History of Diabetes Mellitus & Yes & $124(27.6 \%)$ & $158(35.1 \%)$ & 0.085 \\
& No & $60(13.3 \%)$ & $108(24 \%)$ & \\
\hline
\end{tabular}

*. The Chi-square statistic is significant at the 0.05 level. 
at later half of second trimester. ${ }^{18}$ According to a study carried out in Punjab, prevalence of antenatal depression was $25 \% .{ }^{19}$ In another descriptive cross sectional study conducted in District Chitral, the prevalence of depression was predicted to be $34 \%$ among 340 pregnant women. ${ }^{20}$ In 2007, a study from a tertiary care private hospital in Lahore assessed using Edinburgh Postnatal Depression Scale (EPDS) showed $42.7 \%(n=91)$ of women, scored above the cut-off for antenatal depression. ${ }^{21}$ The results correspond well with this study where the prevalence of depression among women seeking antenatal care during their last trimester according to Goldberg Depression Scale in Shalamar Hospital a private tertiary care institution of Lahore was $40.89 \%$ $(n=184)$.

Passive smoking status was assessed by asking pregnant women if anyone in their house smokes around them during their current pregnancy if yes they were regarded as passive smoker? Passive smoking radically attributes to undesirable psychological wellbeing for women in antenatal phase, particularly due to their rigorous outcome of suicidal thoughts. Shu-Chuan Weng et al. in 2016 examined the association of exposure of passive smoking with suicidal thoughts, anxiety and depression in women from the first three months of pregnancy to the first month of puerperal phase in Taiwan and weighed against with women without antenatal passive smoking exposure. Exposure of passive smoking in pregnant women solitarily demonstrated elevated risks for suicidal thoughts in the second trimester $(\mathrm{OR}=7.63 ; 95 \% \mathrm{CI}=3.25-17.93)$ and third trimester $(\mathrm{OR}=4.03 ; 95 \% \mathrm{CI}=1.76-9.23) .{ }^{22}$ Women with exposure of passive smoking had a greater than before risk of depression $(\mathrm{OR}=1.71$; $95 \% \mathrm{CI}=1.27-2.29)$. The results correspond well with this study where authors found out the association between passive smoking and antenatal depression in last trimester as highly significant $(\mathrm{p}<0.01)$.

Al-Azri et al. (2016)carried out a cross-sectional study in Muscat, Oman on expectant Omani women greater and equal to 32 gestational weeks $(n=959)$ attending primary care health center for scheduled regular antenatal care. It was established that antenatal depression was significantly associated with a positive history of depression among family members $(p=0.019) .{ }^{23}$ The prevalence of family history of depression in our study was higher and almost $16.8 \%(n=76)$ of the women had a family history of depression but the association was significant $(\mathrm{p}<0.05)$.

Rong $\mathrm{Hu}$ et al. in 2015 evaluated twelve studies with self-reported screening tools on antenatal depression and the risk of preeclampsia. Antenatal depression was significantly associated with both Caesarean delivery and preeclampsia $(\mathrm{RR}=1.24$; $95 \% \mathrm{CI}, 1.14-1.35$, and OR $=1.63,95 \% \mathrm{CI}, 1.32$ 2.02 , respectively).$^{24}$ Our study also evaluated that $26.6 \%(n=120)$ had a family history of pre eclampsia and the association between family history of preeclampsia and antenatal depression was highly significant $(\mathrm{p}<0.05)$.

Limitations of the study: It included convenience non probability sampling method. This study has been conducted in a tertiary hospital and the women outside of this tertiary hospital could not be screened for antenatal depression and relevant associations could not be estimated. Goldberg depression scale is a screening not a diagnostic tool. Consequently to confirm any case of depression, referral to a psychiatric panel should be done. It has also not been derived that antenatal depression might or might not proceed as postnatal depression after delivery. Another drawback of the present investigation is that the evaluation of depression was made only once during pregnancy, raising the issue about whether symptoms changed altogether after pregnancy for betterment or worsened.

\section{CONCLUSION}

According to Goldberg Depression Scale, a significantly high percentage $(41 \%)$ of women seeking antenatal care in their last trimester of pregnancy appearing in private tertiary care institution of Lahore suffered from Depression. The association between passive smoking and antenatal depression in last trimester was highly significant. Moreover, history of preeclampsia and family history of depression were also associated with antenatal depression.

Acknowledgments: The authors would like to thank the staff nurse Ms. Shahida Siddique, Radiology Assistant, Ayesha Tariq and Dr. Faisal Nadeem Khan, Consultant Radiologist for their help and assistance in this study.

Grand Support and Financial Disclosures: None. 


\section{REFERENCES}

1. Hiremath P. Need for psychological assessment during pregnancy-A nursing perspective. Glob J Nurs Forensic Stud [Internet]. 2016;1(7):1-4.

2. Bernard-Bonnin AC. Maternal depression and child development. Paediatr Child Health. 2004;9(8):575-583. doi: $10.1093 / \mathrm{pch} / 9.8 .575$

3. Pilling S, Anderson I, Goldberg D, Meader N, Taylor C, Two Guideline Development Groups. Depression in adults, including those with a chronic physical health problem: summary of NICE guidance. BMJ. 2009;339:b4108. doi: 10.1136/bmj.b4108

4. World Health Organization, The Global Burden of Disease, WHO, Geneva, Switzerland, 2008.

5. Thompson O, Ajayi I. Prevalence of antenatal depression and associated risk factors among pregnant women attending antenatal clinics in Abeokuta North Local Government Area, Nigeria. Depress Res Treat. 2016;2016:4518979. doi: 10.1155/2016/4518979

6. Dayan J, Creveuil C, Marks MN, Conroy S, Herlicoviez M, Dreyfus M, Tordjman S. Prenatal depression, prenatal anxiety, and spontaneous preterm birth: A prospective cohort study among women with early and regular care. Psychosomatic Med. 2006;68(6):938-946. doi:10.1097/01. psy.0000244025.20549.bd

7. Orr ST, James SA, Blackmore Prince C. Maternal prenatal depressive symptoms and spontaneous preterm births among African-American women in Baltimore, Maryland. Am J Epidemiol. 2002;156(9):797802. doi:10.1093/aje/kwf131

8. Rahman A, Iqbal Z, Bunn J, Lovel H, Harrington R. Impact of maternal depression on infant nutritional status and illness: a cohort study. Arch Gen Psychiatry. 2004;61(9):946952. doi:10.1001/archpsyc.61.9.946

9. Evans J, Heron J, Patel RR, Wiles N. Depressive symptoms during pregnancy and low birth weight at term. Br J Psychiatry. 2007;191(1):84-85. doi:10.1192/bjp.bp.105.016568

10. Field T, Diego M, Hernandez-Reif M. Prenatal depression effects on the fetus and newborn: A review. Infant Behav Dev. 2006;29(3):445-455. doi:10.1016/j.infbeh.2006.03.003

11. Haas DM, Weida J, Smith R, Abernathy MP. A comparison of depression symptoms and histories in pregnant women. J Reprod Med. 2011;56(1-2):39-43.

12. Vollebergh WA, Iedema J, Bijl RV, de Graaf R, Smit F, Ormel $\mathrm{J}$. The structure and stability of common mental disorders: the NEMESIS study. Arch Gen Psychiatry. 2001;58(6):597603. doi:10.1001/archpsyc.58.6.597

13. Newport DJ, Levey LC, Pennell PB, Ragan K, Stowe ZN. Suicidal ideation in pregnancy: Assessment and clinical implications. Arch Women's Mental Health 2007;10(5):181-187.

14. Pereira PK, Lovisi GM, Pilowsky DL, Lima LA, Legay LF. Depression during pregnancy: Prevalence and risk factors among women attending a public health clinic in Rio de Janeiro, Brazil. Cadernos de Saúde Pública. 2009;25:2725-2736.
15. Felice E, Saliba J, Grech V, Cox J. Prevalence rates and psychosocial characteristicsassociated with depression in pregnancy and postpartum in Maltese women. J Affect Disord. 2004;82(2):297-301. doi:10.1016/j.jad.2003.11.011

16. Shah SM, Bowen A, Afridi I, Nowshad G, Muhajarine N. Prevalence of antenatal depression: Comparison between Pakistani and Canadian women. J Pak Med Assoc. 2011;61(3):242-246.

17. Humayun A, Haider II, Imran N, Iqbal H, Humayun N. Antenatal depression and its predictors in Lahore, Pakistan. East Mediterr Health J. 2013;19:327-332.

18. Karmaliani R, Asad N, Bann CM, Moss N, Mcclure EM, Pasha $\mathrm{O}$, et al. Prevalence of Anxiety, Depression and Associated Factors among Pregnant Women of Hyderabad, Pakistan. Int J Soc Psychiatry. 2009;55(5):414-424. doi: $10.1177 / 0020764008094645$.

19. Rahman A, Iqbal Z, Harrington R. Life events, social support and depression in childbirth: Perspectives from a rural community in the developing world. Psychological Med. 2003;33(7):1161-1167. doi:10.1017/S0033291703008286

20. Shehzad S, Farooq S, Parpio Y, Asad N, Syed IA, Pasha O. Factors affecting depression among married women living in urban squatter settlements of Karachi, Pakistan. Open J Epidemiol. 2016;6(1):80-87. doi:10.4236/ojepi.2016.61008

21. Imran N, Haider II. Screening of antenatal depression in Pakistan: Risk factors and effects on obstetric and neonatal outcomes. Asia-Pacific Psychiatry. 2010;2(1):26-32. doi:10.1111/j.1758-5872.2009.00028.x

22. Weng SC, Huang JP, Huang YL, Lee TSH, Chen YH Effects of tobacco exposure on perinatal suicidal ideation, depression, and anxiety. BMC Public Health. 2016;16(1):623. doi:10.1186/s12889-016-3254-z

23. Al-Azri M, Al-Lawati I, Al-Kamyani R, Al-Kiyumi M, Al-Rawahi A, Davidson R, et al. Prevalence and Risk Factors of Antenatal Depression among Omani Women in a Primary Care Setting: Cross-sectional study. Sultan Qaboos Univ Med J. 2016;(1):e35-e41. doi: 10.18295/squmj.2016.16.01.007.

24. Hu R, Li Y, Zhang Z, Yan W. Antenatal DepressiveSymptoms and the Risk of Preeclampsia or Operative Deliveries: A Meta-Analysis. PLoS ONE. 2015;10(3):e0119018. doi:10.1371/journal.pone.0119018.

\section{Author`s Contribution:}

MLFN conceived, designed and did statistical analysis and editing of manuscript.

MS did data collection and manuscript writing. THK did review and final approval of manuscript.
Authors:

1. Dr. Mahrukh Sabir, MBBS,

2. Dr. Muhammad Luqman Farrukh Nagi, MBBS, MPH(Australia),

3. Dr. Tahseen Haider Kazmi, MBBS, MPH(Australia), FCPS

1-3: Department of Community Medicine,

Shalamar Institute of Health Sciences,

Lahore, Pakistan. 